$\begin{gathered}\text { Revista do Departamento de Geografia } \\ \text { Universidade de São Paulo } \\ \text { www.revistas.usp.br/rdg }\end{gathered}$
Volume Especial - XVII SBGFA / I CNGF (2017)

\title{
Espacialização de Inundações na Foz do Rio Jacuí por NDWI e Reclass em Episódios de EI Niño
}

\author{
Spatization of Floods on the Jacuí River by NDWI and \\ Reclass at El Niño Episodes
}

\author{
Pedro Teixeira Valente \\ Universidade Federal do Rio Grande do Sul \\ peixeira.valente@gmail.com \\ Francisco Eliseu Aquino \\ Universidade Federal do Rio Grande do Sul \\ francisco.aquino@ufrgs.br \\ Venisse Schossler \\ Universidade Federal do Rio Grande do Sul \\ venisse.schossler@ufrgs.br
}

Recebido (Received): 18/03/2016

DOI: $10.11606 /$ rdg.v0ispe.132733
Aceito (Accepted): 06/06/2017
Resumo: Este trabalho visa espacializar as áreas de inundação da foz do rio Jacuí durante a ocorrência de dois eventos extremos de precipitação, em episódios de El Niño (setembro de 1987 e setembro de 2009) por meio de duas técnicas de delimitação de alvos no software IDRISI Selva 17: NDWI e Reclass. Foi observado que as enchentes não estão diretamente relacionadas a eventos de El Niño e, apesar do fenômeno influenciar na precipitação do Rio Grande do Sul (Brasil), os fatores locais como a topografia e o próprio regime de precipitação originam estas anomalias. Por fim, foi feita uma comparação dos dois eventos, onde se observa que a enchente de 2009 alagou uma área maior que a de 1987, sendo 435 e $368 \mathrm{~km}^{2}$, respectivamente. A provável razão do aumento da área alagada foi o crescimento do cultivo de arroz nas regiões situadas na jusante do Jacuí, que diminui as áreas úmidas, removendo as barreiras de contenção do rio. O estudo foi feito através de imagens Landsat 5 - TM. Os mapas foram elaborados nos softwares ArcGis 10.2 e IDRISI Selva. Também foi observada neste trabalho a relação das cheias com as plantações que contornam a margem do Jacuí, arroz em sua grande maioria.

Palavras chave: Áreas úmidas; Sensoriamento Remoto; eventos extremos de precipitação; Teleconexões.
Abstract: This work aims spatialise the flood areas of the Jacui river mouth during the occurence of two extreme precipitation events, in two El Niño episodes: september 1987 and september 2009 using two target delimitation techniques in IDRISI 17 SELVA: NDWI and Reclass. After that, the results were adjusted in ArcGis 10.2 layout. It was found that the floods are not directly related to El Niño events and that despite this phenomenon influence the precipitation of Rio Grande do Sul (Brazil), local factors such as topography and the actual precipitation system provides these anomalies. Finally, it was made a comparison of the two events, where it is perceived that the flood 2009 covers a larger area $\left(435 \mathrm{~km}^{2}\right)$ than the flood of $1987\left(368 \mathrm{Km}^{2}\right)$. The probable reason for this increase in the flooded area is due to the increase in the used area for agriculture, which removes the wetlands, removing the barrier that contains the river.

Keywords: Wetlands; Remote Sensing; Extreme Precipitation Events; Teleconnections. 


\section{INTRODUÇÃO E OBJETIVOS}

As inundações são originadas por eventos climáticos extremos e constituem-se em fenômenos de ocorrência natural em todos os ambientes fluviais (CASTRO, 1998; OLIVEIRA, 2010). É comum que estas anomalias afetem áreas urbanas e de cultivo localizadas próximas a estes ambientes, atingindo casas, bens materiais, plantações e, em alguns casos, levando a perdas humanas. A foz do rio Jacuí possui cidades em ambas as margens, e comumente são alagadas em períodos de cheia.

Áreas úmidas estão propensas a sofrerem episódios de inundação devido a sua proximidade a grandes corpos d'água. Logo, torna-se imprescindível conhecer o comportamento destes sistemas, espacialmente e (principalmente) temporalmente, para se determinar os limites médios dos eventos extremos de cheia. Há várias formas e técnicas de se determinar o impacto de um evento de inundação. Neste contexto, o sensoriamento remoto mostra-se uma importante ferramenta para a delimitação da área afetada pelas águas.

O El Niño é um fenômeno decorrente do aquecimento anômalo das águas do oceano Pacífico Equatorial (TRENBERTH, 1997; KOUSKY E BELL, 2000). Contudo, seus efeitos são sentidos em diferentes partes do planeta. Na foz do rio Jacuí, assim como em todo o estado do Rio Grande do Sul (RS), esta teleconexão costuma alterar os regimes de precipitação, trazendo consigo eventos com valores próximos ao dobro da média local de precipitação. Fontana e Berlatto (1997) apontam que, no RS, as inundações históricas costumam coincidir com os episódios de El Niño.

O objetivo deste trabalho consiste em espacializar a área de inundação da foz do rio Jacuí durante a ocorrência de dois eventos extremos de precipitação utilizando as técnicas de delimitação de alvos NDWI e Reclass. Após, será feita uma comparação a fim de se avaliar qual das duas técnicas é mais eficiente para esta prática.

\section{APORTE TEÓRICO}

\section{Rio Jacuí}

Segundo a FEPAM (2002), a bacia hidrográfica do rio Jacuí tem área de $71.600 \mathrm{~km}^{2}$, que corresponde a $83,5 \%$ da área da região hidrográfica do Guaíba. O rio Jacuí nasce no Planalto, nos municípios de Passo Fundo e Marau, e toda a sua área de drenagem caracteriza-se pelo uso intensivo do solo para agricultura.

O rio Jacuí tem suas principais nascentes localizadas no Planalto, cerca de $10 \mathrm{~km}$ a leste da cidade de Passo Fundo, numa altitude aproximada de $730 \mathrm{~m}$. Seu comprimento total aproximado é de $710 \mathrm{~km}$. Corre, na direita, o rio Jacuí-mirim; muda para a direção sul até a Depressão Central, onde recebe as águas dos rios Vacacaí-mirim e Vacacaí na margem direita. Toma a direção oeste-leste, com a denominação de Baixo Jacuí recebe a contribuição do rio Taquari na margem esquerda, e percorrendo cerca de $300 \mathrm{~km}$ até sua foz, com e formação do Delta do Jacuí, onde desembocam os rios Gravataí, Sinos e Caí. A precipitação média anual na bacia é variável, atingindo $1.600 \mathrm{~mm}$ no seu valor mais alto, nas zonas compreendidas pelo curso principal do rio Jacuí até a foz do Jacuizinho e pelas cabeceiras do rio das Antas. O seu valor mais baixo, em torno de 1.200 mm anuais, encontra-se na zona compreendida pelo curso principal do rio Jacuí, entre Dona Francisca e a confluência com o rio.

Os principais contribuintes do Jacuí, em sua margem direita, são os rios Jacuí-mirim, Ivaí, Vacacaí; e, na margem esquerda, os rios Jacuizinho, Pardo e Taquari, único afluente presente neste trabalho. Na área de drenagem da bacia do Jacuí encontram-se aglomerações urbanas de porte significativo, destacando as cidades de Santa Maria (face leste), Cachoeira do Sul, Rio Pardo, São Jerônimo, Triunfo, Charqueadas, Bento Gonçalves (drena para o rio das Antas), Lajeado (rio Taquari), Estrela (rio Taquari) e Taquari (rio Taquari).

$\mathrm{Na}$ área norte do rio Jacuí predominam as culturas intensivas de soja e trigo, pelo sistema de cultura rotativa. Na área sul aparece, além destas culturas, o cultivo do arroz e um incremento da pecuária. Também no trecho final do rio Jacuí destacam-se as atividades de mineração de carvão e operação de usinas termelétricas à carvão.

\section{El Niño}

O El Niño-Oscilação Sul (ENOS) origina-se do aquecimento anômalo do Pacífico Equatorial que, juntamente com o enfraquecimento dos ventos alísios, altera os padrões de chuva e temperatura em diversos 
locais do globo (BARRY E CHORLEY, 2013). Já nos episódios de La Niña, fase oposta ao El Niño, há um maior fortalecimento dos ventos alísios, relativo a outra fase, que represa as águas quentes do Pacífico Equatorial na costa asiática. Contudo, nem todos os casos apresentam o mesmo comportamento. Em anos de El Niño é comum que os totais pluviométricos estejam acima da média no sudeste da América do Sul (TRENBERTH, 1997; FONTANA E BERLATO, 1997; OLIVERIRA, 1999).

O ciclo de ambas as fases não é bem definido, variando entre dois e sete anos (BARRY E CHORLEY, 2013; TRENBERTH, 1997; OLIVEIRA, 1999; MARENGO et al., 2007; GRIMM, 2009). A variabilidade interanual é um aspecto marcante na precipitação do sudeste da América do Sul. Segundo Grimm (2009, p. 259), na região sul do Brasil o clima apresenta grandes contrastes na precipitação e temperatura devido a influência do ENOS.

\section{MÉTODOS E TÉCNICAS}

\section{Área de Estudo}

Como já dito anteriormente, a área estudada corresponde à foz do rio Jacuí, do seu encontro com o rio Taquari até sua foz, onde se forma o seu delta, conforme descrito na Figura 1. Nesta região existem quatro municípios nas margens de ambos os rios, sendo eles São Jerônimo, Charqueadas, Triunfo e General Câmara. Além das cidades, há muitas áreas de cultivo de arroz e outros grãos ao seu redor que são comumente alagadas em períodos de cheia. $\mathrm{O}$ trecho analisado do rio possui, aproximadamente, $75 \mathrm{~km}$ de comprimento, abrangendo uma área, normalmente, em torno de $156 \mathrm{~km}^{2}$.

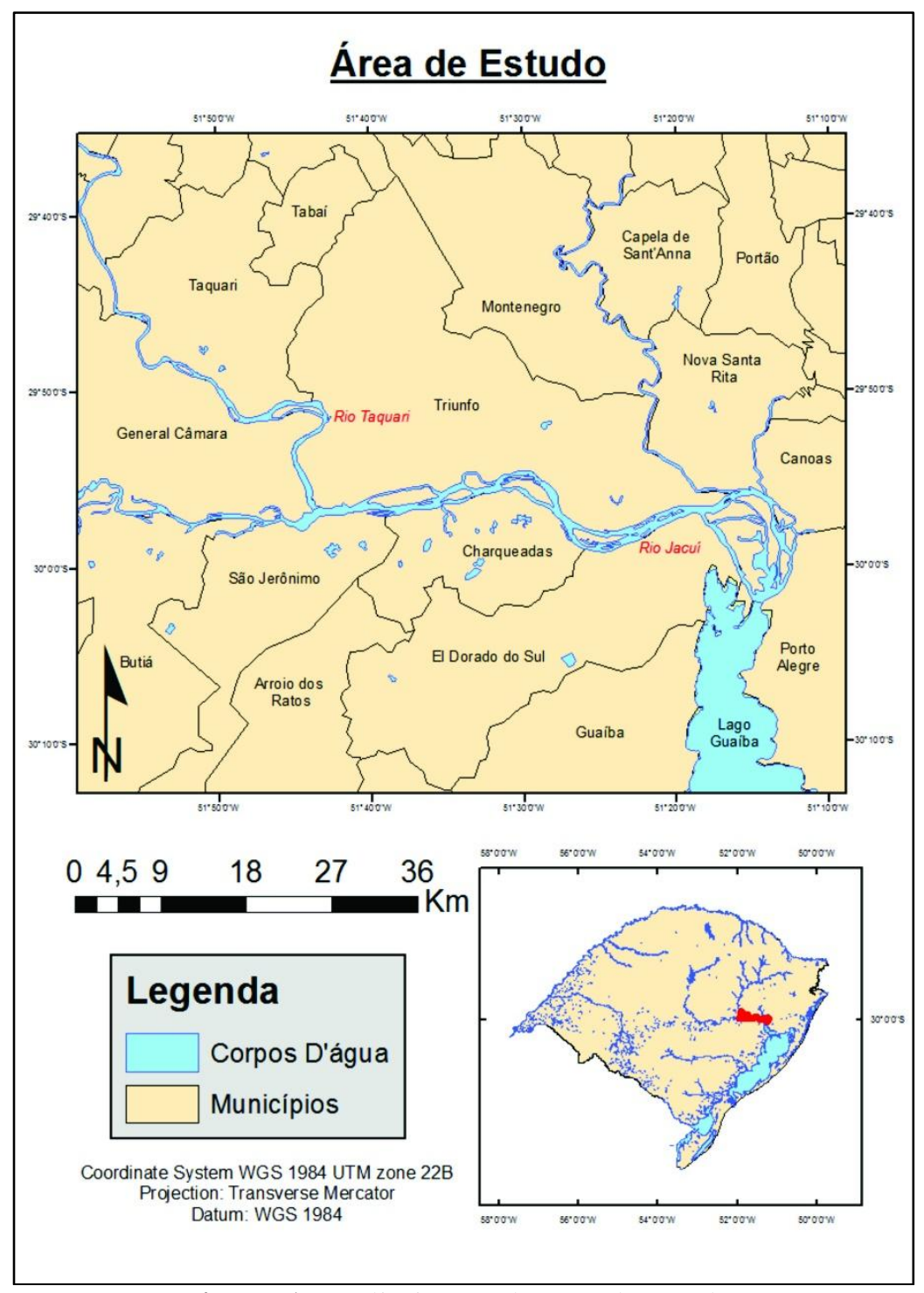

Figura 1 - Delimitação da área de estudo. 
Para a comparação das técnicas e das inundações, foram utilizadas três imagens Landsat 5 - TM, datadas de 08/09/1987 (período de cheia), 03/09/1991 (rio em seu estado normal) e 20/09/2009 (período de cheia). A escolha do mês de setembro se deve ao fato deste ser o mês apresentar um dos maiores índices de precipitação do estado (FONTANA E BERLATTO, 1997). Contudo, devido à alta faixa de nebulosidade apresentada nas imagens, a distância temporal entre estas acabou ultrapassando dez anos.

Outro critério importante para a seleção das cenas, principalmente as imagens de cheia, foi o período de El Niño. Ambas as cheias necessitavam estar em períodos de El Niño semelhantes, ou seja, o oceano Pacífico precisava estar nos mesmos padrões de temperatura. Para isto, utilizou-se o índice Niño 3.4, fornecido pelo Climate Prediction Center (CPC), da National Oceanic and Atmospheric Administration (NOAA), nos Estados Unidos. O Niño 3.4, região do oceano Pacífico Equatorial do qual são medidas as variáveis observadas, (NOAA, 2015) apresenta os índices de anomalias de temperatura de superfície do mar (TSM) do oceano Pacífico. Quando os valores se encontram superiores a $0.5^{\circ} \mathrm{C}$ significa que há a ocorrência de um evento de El Niño. Por sua vez, quando estes valores se encontram inferiores a $-0,5^{\circ} \mathrm{C}$ ocorre um evento de La Niña. Para os meses de setembro de 1987, setembro de 1991 e setembro de 2009 os valores do Niño 3.4 são de 1.6, 0.7 e 0.7, respectivamente. Ressalta-se que, mesmo em período de El Niño, a imagem de 1991 apresenta o rio em seu estado normal. Isto decorre porque o El Niño não é o único mecanismo que altera os padrões de precipitação do RS.

\section{NDWI}

O NDWI (Normalized Difference Water Index) ou Índice de Diferença Normalizada da Água é uma técnica do sensoriamento remoto utilizada para discriminar ambientes com águas expostas. Por exemplo, Brenner e Guasselli (2015) delimitaram os meandros ativos do rio Gravataí (RS) pelo NDWI. Basicamente, o NDWI é obtido através das bandas do verde e do Infravermelho Médio, no Landsat 5 (JI et al., 2009). A Equação 1 expressa a sua aplicação, onde as variáveis TM2 e TM4 representam as bandas do Verde e do Infravermelho Próximo, respectivamente.

$$
N D W I=(T M 2-T M 4) /(T M 2+T M 4) \quad \text { Equação } 1 .
$$

De acordo com Mc Feeters (1996), a técnica do NDWI permite: a) maximizar a reflectância típica da água utilizando o comprimento de onda do verde; b) minimizar a baixa reflectância dos corpos de agua no infravermelho próximo; e c) realçar o contraste entre a agua e a cobertura vegetal, proporcionada pelo infravermelho próximo.

Os valores resultantes do processo de NDWI variam de -1 a 1 , tendo o zero como limiar (MC FEETERS, 1996). Logo, valores abaixo de zero são contabilizados como não água (vegetação, solo exposto, areia, etc.) e valores superiores a zero são registrados como água.

\section{Reclass}

Assim, como o NDWI, o Reclass também é utilizado para discriminar os alvos em imagens. Contudo, sua metodologia é muito mais simples que a do NDWI. O Reclass basicamente consiste em uma ferramenta de classificação da imagem conforme o objetivo do programador. Com ele, pode-se reclassificar a imagem por altitude, feições, declividade, etc. Enfim, esta técnica permite que se classifique a imagem em grupos, conforme o objetivo da pesquisa.

Como o propósito deste estudo é classificar áreas de inundação, as imagens foram classificadas em apenas dois grupos: água e terra. Para isto, basta dizer ao software o número de classes que você deseja separar a imagem e ele, avaliando os padrões de feição da imagem, faz a divisão.

É importante ressaltar que, neste caso, as imagens Reclass foram geradas a partir das imagens NDWI, pois estas já haviam descriminado a água dos outros alvos. Contudo, também se ressalta que isto foi feito com a finalidade de comparar os produtos finais de cada um para se perceber qual deles é mais adequado para a delimitação de áreas de inundação. Por fim, sobressalta-se que os mapas foram desenvolvidos nos softwares ArcGis 10.2 (área de estudo) e IDRISI Selva 17 (NDWI e Reclass). 


\section{RESULTADOS}

\section{NDWI}

A Figura 2 apresenta as imagens NDWI processadas. A Figura 2B (1991), apresenta o rio Jacuí no seu estado normal. Por sua vez, as Figuras 2A e 2C referem-se aos eventos de cheia, dos anos de 1987 e 2009, respectivamente. No primeiro evento anômalo, percebe-se que o grande foco da enchente ocorre nas áreas de cultivo de arroz próximas ao delta. Evidencia-se, porém, que o rio Jacuí não é o único a inundar este lugar, visto que os rios Caí e Sinos também se encontram inundados. Contudo, o meandro do rio Jacuí anterior ao delta sofre influência direta da vazão deste rio. Além do delta e dos seus entornos, há mais duas áreas alagadas: a primeira está localizada no meandro do rio Taquari, antes do encontro com o rio Jacuí. Neste trecho, as águas inundaram alguns campos próximos à margem do rio. Outro ponto de ocorrência de inundação está localizado no rio Jacuí, a oeste do encontro deste rio com o Taquari. Nele observa-se que a área inundada é equivalente àquela situada antes da sua foz, no delta. Nenhum dos casos apresenta áreas inundadas nas manchas urbanas, estas apenas aparecem em campos próximos às margens.

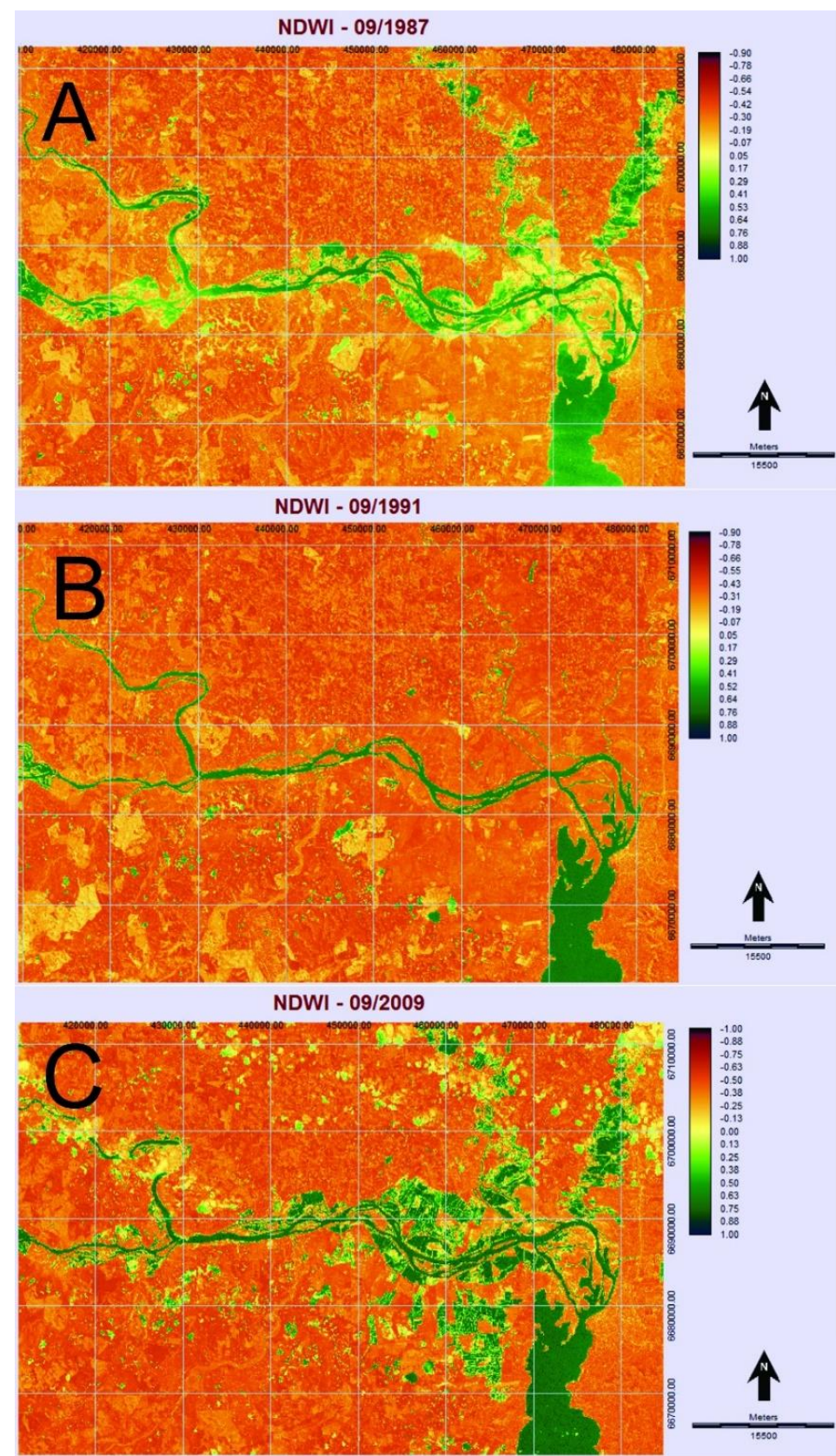

Figura 2 - Composições NDWI. Os valores variam de -1 a 1 , onde valores superiores a 0 representam ambientes dominados pela água, ao passo que valores inferiores a 0 correspondem a outros tipos de alvos. Em A) é destacada a cheia de setembro de 1987; B) um período neutro e em C) a cheia de setembro de 2009. 


\section{Reclass}

A técnica do Reclass (Figura 3) permitiu melhor visualização da área inundada pelos rios, pois esta divide a imagem em apenas duas classes. Apesar dos resultados serem semelhantes aos da Figura 2, ela espacializa as anomalias de forma mais didática, nota-se que os meandros ativos dos rios Jacuí e Taquari concentram os grandes focos de inundação.

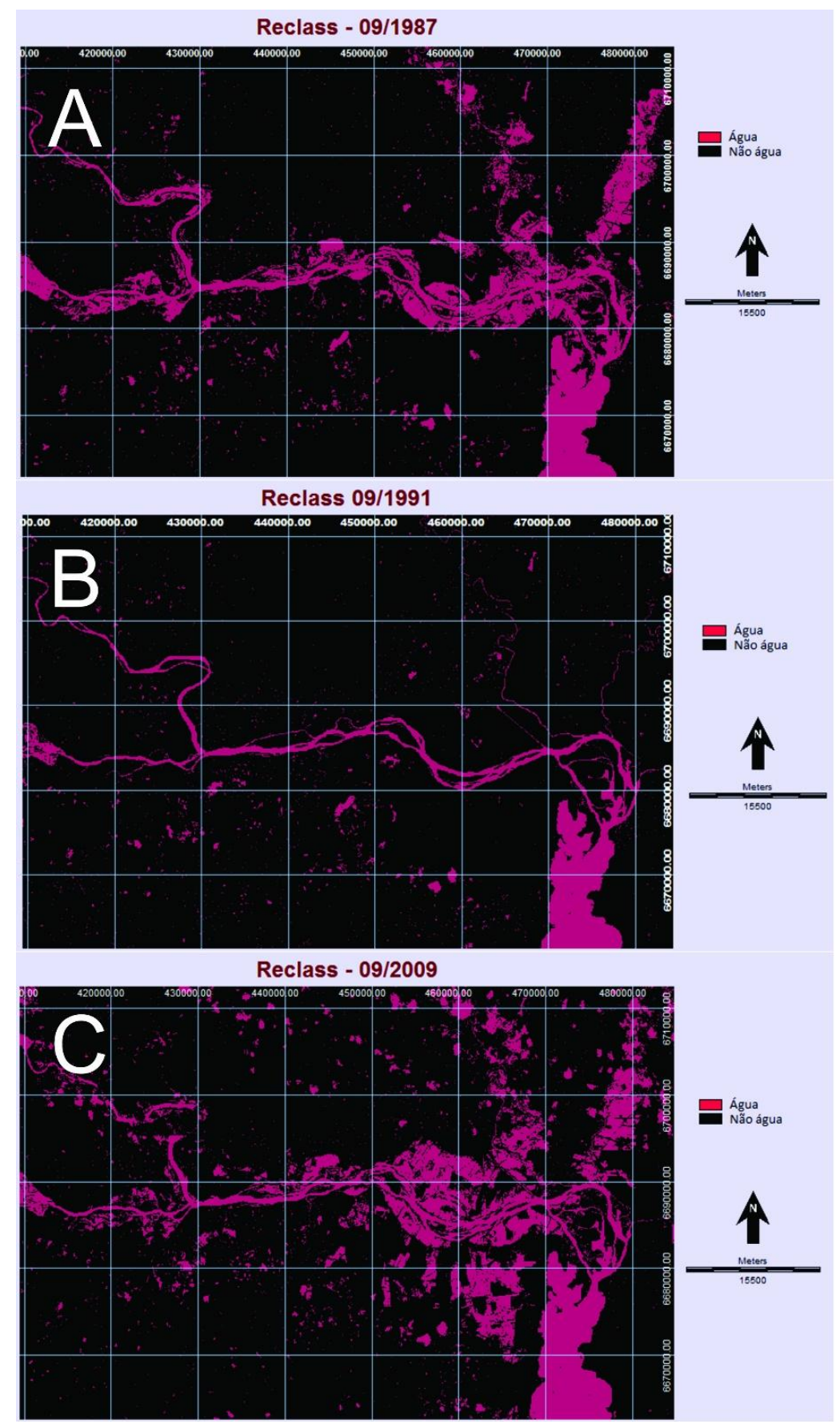

Figura 3 - Composições Reclass. Em A) é possível observar a cheia de setembro de 1987; B) apresenta um período neutro e; C) destaca a cheia de setembro de 2009. Os pontos em rosa referem-se a corpos d'água, sejam eles pontos alagados ou em estado normal, em preto feições que não contem água em sua superfície. 
Próximos a estes meandros encontram as cidades de General Câmara e São Jerônimo e Charqueadas. Segundo as imagens, as áreas urbanas inundadas foram próximas ao rio, não invadindo muitas moradias e lares. Foi realizada uma pesquisa no jornal Correio do Povo com o intuito de procurar por notícias sobre os casos, porém nada foi encontrado. Isto pode indicar que ambos os eventos de inundação não foram prejudiciais às cidades, afetando apenas as áreas cultiváveis.

Destaca-se também o papel do El Niño na atuação destes eventos. Como ambos os eventos ocorreram em período ativo do El Niño, optou-se por encontrar uma imagem do mesmo mês e em evento de mesma magnitude ou semelhante, a fim de mostrar que o ENOS, não necessariamente, é o único fator que influencia nestas chuvas. Comumente, vemos notícias, em períodos onde o ENOS encontra-se ativo, apontando que as chuvas que ocorrem são proporcionadas pelo aquecimento anômalo das águas do oceano Pacífico. Contudo, deve se levar em conta outros fatores que também podem ser importantes, como o relevo e outros processos atmosféricos (frontogênese, jatos, massas de ar, etc.) que formam a dinâmica do local. Para o RS, setembro costuma ser um mês chuvoso. Logo, há uma tendência a ocorrerem inundações neste período (FONTANA E BERLATO, 1997). Em anos de El Niño, pode haver um acúmulo no regime mensal de precipitação, ou seja, chover muito em um curto período de tempo. Se este acúmulo acontecer em uma escala semanal (ou até menor), anomalias de precipitação podem acarretar em inundações severas. As Figuras 3A e 3C são exemplos didáticos da magnitude destes eventos. Contudo, a Figura 3B, também exposta a uma condição de El Niño, não expressa anomalia alguma nos corpos d’água.

Segundo o Instituto Nacional de Ciência e Tecnologia em Áreas Úmidas (INAU) as áreas úmidas são um grande indicativo da capacidade do sistema de conter inundações, pois conseguem acumular o excesso de água na própria planície de inundação, impedindo que esta avance (CUNHA et al, 2015). As atividades agrícolas, no entanto, costumam utilizar estas áreas para produção, dadas as características favoráveis à plantação de determinados grãos. Isto pode amplificar os danos dos eventos extremos, pois, com estas áreas úmidas alteradas, o amortecimento passa a não ser mais o mesmo. Logo, a água consegue alcançar terrenos mais distantes a cada pulso de inundação. De acordo com Junk et al (1989) o pulso de inundação define, analisa e explica o intercâmbio lateral de água, nutrientes e organismos entre rios ou lagos e as respectivas áreas alagáveis conectadas, definindo processos e padrões de assinatura hidrológica na mudança das condições ecológicas entre a fase terrestre e a aquática.

As Figuras 3 e 4 demonstram o impacto que eventos extremos de inundação ocasionam em plantações, quando mal preservados. Na Figura 4 avalia-se a diferença de áreas alagadas entre as duas enchentes. Nota-se, nitidamente, que a grande diferença entre os dois episódios ocorre na área cultivada próxima ao delta do Jacuí. Houve uma expansão do cultivo de arroz entre as duas inundações, o que pode ser verificado nas imagens NDWI da Figura 2. No ano de 1987, observa-se a existência de um banhado na região, que posteriormente foi alterado para a produção de arroz. Com a expansão da área cultivável, também se expandiu a área alagável, fazendo com que a inundação de 2009 alagasse uma área maior. Em números, a área alagada na enchente de 1987 corresponde a $368 \mathrm{~km}^{2}$, ao passo que, em 2009, o episódio extremo alagou $435 \mathrm{~km}^{2}$. Isto indica que a expansão da área agrícola e a degradação das áreas úmidas podem ser um fator determinante na redução dos impactos das grandes inundações. 


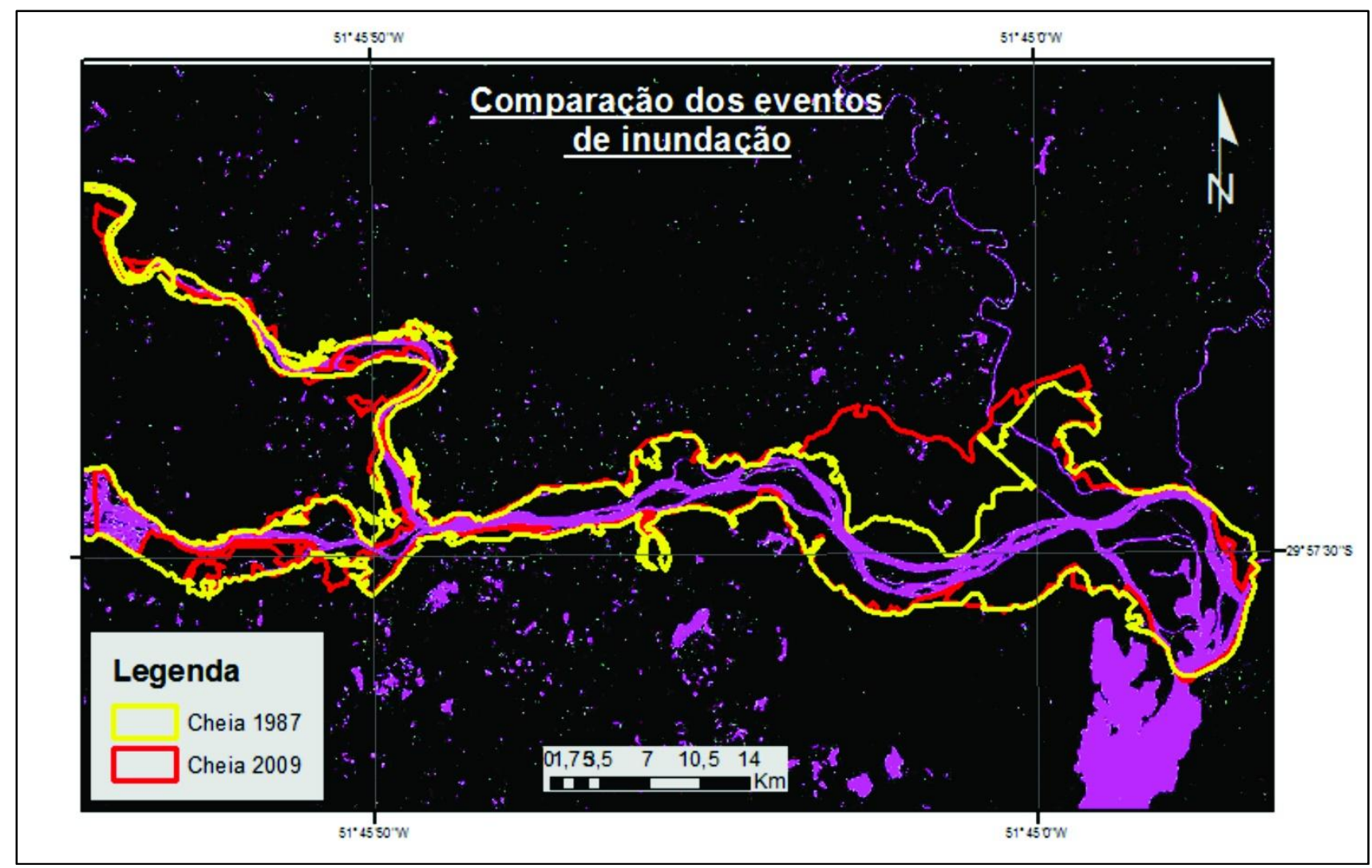

Figura 4 - Comparação dos dois eventos extremos de inundação.

\section{CONCLUSÕES}

Após analisar os dois eventos de inundação, conclui-se que estes não estão diretamente relacionados ao fenômeno ENOS. Isto se explica pelo fato dos três períodos analisados (cheias e normal) estarem em episódios de El Niño. Ou seja, a imagem de 1991, que apresenta o trecho do rio em estado normal, possui as mesmas características de El Niño que as imagens de cheias. Como citado anteriormente, os valores do índice Niño para os meses de setembro de 1987, 1991 e 2009, são 1,6; 0,7 e 0,7, respectivamente. Logo, percebe-se que a intensidade do fenômeno ENOS não altera diretamente o regime das águas do rio Jacuí nestes três casos. Ela pode cooperar intensificando os regimes de precipitação, como em 1987 e 2009, mas não significa que todo evento de El Niño acarretará em uma inundação no rio Jacuí. Fontana e Berlato (1997) afirmam que eventos ENOS, mesmo que possuam intensidades similares, não necessariamente terão os mesmos resultados, pois há outras variáveis atmosféricas que influem paralelamente às mudanças do ENOS.

O fato de uma parte das áreas úmidas serem transformadas em áreas de cultivo afeta diretamente a dinâmica fluvial das margens dos rios, como neste caso. O aumento da área cultivável causa a remoção de um sistema que anteriormente servia como amortecedor da água excedente que escoava pelo rio. Removendo esta área, a água pode se expandir por um perímetro maior, alagando áreas que antigamente não eram inundadas. As metodologias aplicadas mostram-se competentes para a delimitação das áreas inundadas. A técnica do Reclass demonstra maior eficácia, visto que ela discrimina os alvos em apenas duas classes, evidenciando desta maneira a água. Contudo, a técnica do NDWI é tão útil quanto, seja para ressaltar a lâmina d'água como para determinar a sua turbidez. A união das duas técnicas permitiu uma observação mais precisa da área inundada. Destaca-se que este estudo não visa comparar as duas técnicas, mas sim demonstrar que ambos os métodos são úteis para este tipo de análise e estão disponíveis em softwares acessíveis. A execução das tarefas em dois ambientes diferentes permitiu mesclar as técnicas de ambos os softwares, facilitando a realização desta pesquisa. 


\section{BIBLIOGRAFIA}

BARRY, R.; CHORLEY, R. 2013. Atmosfera, tempo e clima. 9a ed. Porto Alegre: Bookman, 2013, 512 pp.

BRENNER, V.C.; GUASSELLI, L.A.; Índice de diferença normalizada da água (NDWI) para identificação de meandros ativos no leito do canal do rio Gravataí/RS - Brasil. In: Simpósio Brasileiro de Sensoriamento Remoto, 17; 2015, João Pessoa - PB, Brasil. pp. 3693-3699.

CHRISTTOFOLETTI, A. 1999. Modelos sobre mudanças e dinâmica evolutiva dos sistemas. In: ANTONIO CHRISTOFOLETTI. Modelagem de sistemas ambientais. São Paulo, Edgard Blücher, 1999. $234 p$.

CUNHA, C.N.; PIEDADE, M.T.F.; JUNK, W. J. Classificação e Delineamento das Áreas Úmidas Brasileiras e seus Habitats. 1aEd. Cuiabá: Edufmt, 2015. 165p.

FEPAM, Qualidade das águas da bacia do rio Jacuí. Net, Porto Alegre, Abr. 2002. Disponível em < http://www.fepam.rs.gov.br/qualidade/qualidade_jacui/jacui.asp>. Acessado em: 04 ago 2016, 15:15.

FONTANA, D.C.; BERLATO, M.A. Influência do El Niño Oscilação Sul sobre a precipitação pluvial no Estado do Rio Grande do Sul. Revista Brasileira de Agrometeorologia, Santa Maria, v.5, n.1, p.127-132, 1997.

GRIMM, A. Clima da região sul do Brasil. In: CAVALCANTI I.F.A., FERREIRA, N.J., SILVA, M.G.A.J., DIAS, M.A.F. Tempo e clima no Brasil. São Paulo: Oficina de Textos, p.259 -275, 2009.

JI, L.; ZHANG, L.; WYLIE, B. Analysis of Dynamic Thresholds for the Normalized Difference Water Index. Photogrammetric Engineering \& Remote Sensing Vol. 75, No. 11, November 2009, pp.13071317.

JUNK, W.J.; BAYLEY, P.B.; SPARKS, R.E. (1989). The Flood Pulse Concept in River-FloodplainSystems. Canadian Special Publications for Fisheries and Aquatic Sciences, 106:110-127p.

KOUSKY, V.E.; BELL, G.D. 2000. Causes, predictions and outcome of El Niño 1997-1998. In: Changnon, S.A. (ed), El Niño 1997-1998, New York: Oxford University, p. 28-48.

MARENGO, J.A. et al. 2007. Mudanças climáticas globais e seus efeitos sobre a biodiversidade. Caracterização do clima atual e definição das alterações climáticas para o território brasileiro ao longo do século XXI. 1a ed. Brasília: Ministério do Meio Ambiente. v. 1., p. 185.

McFEETERS, S.K. The use of the Normalized Difference Water Index (NDWI) in the delineation of open water features. International Journal of Remote Sensing, v.17, n.7, p.1425-1432, 1996.

NOAA. Historical El Niño/La Niña episodes. Net, Maryland, 2017. Disponível em: < http://www.cpc.ncep.noaa.gov/products/analysis_monitoring/ensostuff/ensoyears.shtml>. Acessado em: 12 ago 2016, 16:12.

OLIVEIRA, G.G. Modelos para previsão, espacialização e análise das áreas inundáveis na bacia hidrográfica do rio Caí, RS. Dissertação (Mestrado em Sensoriamento Remoto) - Centro Estadual de Pesquisas em Sensoriamento Remoto e Meteorologia, UFRGS, 148p. 2010.

OLIVEIRA, G.S. 1999. O El Niño e você: o fenômeno climático. São José dos Campos: Transect Editorial, 116pp.

TRENBERTH, K.E. 1997. The definition of El Niño. Bulletin of the American Meteorological Society, v.78 (12), p. 2771-2777.

VALENTE, P.T. Identificação das Áreas mais Sujeitas a Eventos Extremos de Temperatura e Precipitação no Sudeste da América do Sul. Trabalho de conclusão de curso (Bacharelado em Geografia) Universidade Federal do Rio Grande do Sul, 55p. 2015. 